If the imaginary did not exist, one would have to invent it. And in so many ways, we have: the imaginary functions as a sort of a reality-producing device that is irreducible to psychological or sociological methods of explanation. In contrast to those explanations, the imaginary becomes a much more interesting entity when considered as a technique with various histories and different institutional situations. In other words, the imaginary is rehearsed and practiced as well as institutionalized across sites, from libraries to laboratories. This is echoed in Michel Foucault's argument that

the imaginary is not formed in opposition to reality as its denial or compensation; it grows among signs, from book to book, in the interstice of repetitions and commentaries; it is born and takes shape in the interval between books. It is the phenomena of the library.2

Foucault, discussing Gustave Flaubert, places the imaginary in relation to a specific media technique of fabulation by way of written words, a seriality of signs that resonates with how he pitches the project of archaeologies of knowledge as the establishment of discursive statements about what can be known and perceived, whether actual or not. In the library, a whole imaginary world can emerge; reading was for a period perceived as such a danger to women that Bovaristic daydreaming was pathologized as an illness of the mind. What other sort of (gendered) illnesses emerge as part of the imaginaries of the library? What other sort of liminal experiences emerge out of media practices that play with boundaries of the actual and the imagined? The list could be long and, besides reading/ writing practices, includes other sorts of fabulations about the world: real, unreal, and of times and spaces that can also be reached outside the design interfaces of the book and the library. 
Imaginaries are often designed to be out of place. They are designed to shift the space of the possible. Both the library and the museum, in different ways, spatially situate the imaginary. But other institutions have also worked and continue to work in similar space-, shape-, and timeshifting manners. 3 This is a shift that also corresponds with the media theoretical narrative of the emergence of technical media: "Once memories and dreams, the dead and ghosts, become technically reproducible, readers and writers no longer need the powers of hallucination. Our realm of the dead has withdrawn from the books in which it resided for so long." 4 The studio would be another obvious contender as a site of the imaginary, but in relation to technical media culture I will focus on another related site that has gained ground again in the past years in art and design: the laboratory. I will address the laboratory as such a place incorporating practices that shift the coordinates of what is possible. The lab has a significant cultural history, both as a real and a fictional site of scientific research that has become much more than the actual practices of experiments and knowledge production: the mythology of the laboratory is itself a trope that escapes from the confines of any "real history" of what laboratories are. In addition, in recent years an increasing amount of humanities and media institutions have pitched themselves as "labs" in design, creativity, and even a sort of imaginary work, or at least a media archaeological sort of reverse-engineering of technologies and cultural narratives about technology. Bureau D'Etudes speaks of a "Laboratory Planet," which, besides designating the twenty- and twentyfirst-century science-military-entertainment-university-complex as the defining planetary situation that installs infrastructures of power and technology, also refers to the laboratorization of knowledge.5 The world's a lab, or at least that's how the I rhetoric justifies contemporary smart cities, university institutions, and hack labs.6

In this context I ask the question: Outside of the library, as the site of daydreaming fabulation and the situated, writtenform imaginary, how do we engage in practices of speculation in media and design labs, which are contemporary places of recreation, imagination, technological practice, and activism? 
Such a question is rather large to be resolved in a short article, as it touches on the assumed tensions between regularity versus unexpected outcomes; experimentation versus standardization; creativity versus routine, and other sorts of assumed polar opposites that form the ways in which scientific and artistic activity is seen to be separated. And yet, in order to avoid such stereotypes about knowledge and creative practices, critical maps of laboratory practices are needed. Such critical maps, genealogies, and investigations are reminiscent of the various ways in which twentieth-century art and design education's laboratorization of the experiment, as well as the "post-studio practice" interest in other spaces and sites of creativity, have offered ways to understand how institutional situations go hand-in-hand with the broad field of creative practice.

The speculative stance that has become part of the media and design lab scene has often assumed future-oriented and progressivist tones ("Inventing the Future," as the MIT Media Lab has been proposing since the 1980s), but I am just as interested in another sort of temporal horizon: inventing the past as well as inventing alternative timescales, or imaginaries of time-shifting. Hence the lab becomes perceived as a place of experimentation with alternative temporalities, where a

I politics of time in post-digital culture emerges.8

II

The laboratory has institutionalized itself as a key place of invention. As Alfred N. Whitehead put it early in the twentieth century, it is not only isolated technologies like the steam engine that define the special advanced nature of modernity but the method itself:

The greatest invention of the nineteenth century was the invention of the method of invention. A new method entered into life. In order to understand our epoch, we can neglect all the details of change, such as railways, telegraphs, radios, spinning machines, synthetic dyes. We must concentrate on the method itself; that is the real novelty, which has broken up the foundations of the old civilisation.9 
Whitehead shifts the focus from considering science as a purely cognitive contemplation of new ideas to something akin to a mine or geological investigation of ideas that deals with more than just scientific statements and propositions. Also, “an intense period of imaginative design" is needed for ideas to become products, Whitehead continues, sounding more like a prototypical design thinker than a process philosopher.10 Such techniques also include the institutionalization of specific places as part of the emergence of research universities and other places of experimental work.11 Laboratories became standardized as one core feature of chemical and physical science activity, but also engineering work: the Menlo Park laboratories led by Thomas A. Edison were the much debated hub of creative engineering and business ventures, while the laboratory of Nikola Tesla became a parallel sort of a mythologized place of the lone (male) creator of technological marvels.12 The method of invention was also a site of invention that resonated with the parallel spaces of the studio (as in artistic creativity) and the seminar/library (as in the humanities) but with a distinct set of experimental heritage that it carried with it.

Edison was a symptomatic figure, managing to be both an idealized lone genius and also be supported by the collective of experts and facilities at Menlo Park since 1876. Even before Menlo Park, Edison was very acutely aware of what he needed for his early version of a media lab, calling for "every conceivable variety of Electric Apparatus, and any quantity of Chemicals for experimentation." 13 However, it was surely not only the kit or the experimental setup that defined the emerging tech lab, but the new forms of management that defined the emerging methods of science-cum-engineering-cum-media reality of the twentieth century.14

Bruno Latour has written of the effective power of the laboratory as a site of shifting scales. The gradual turn in the understanding of science as a situated practice where the experiment is itself also part of a variety of social considerations forms a particular situation of trial and error, containment and distribution. As Latour outlines, the power of the lab resides in its possibilities as a place of trial and error that gathers its special powers of scale from the interface with the outside world. 
He discusses the role of the lab in Louis Pasteur's nineteenthcentury microbe farming and its massive social consequences as related to its spatial properties, which are about controlling the practices of temporality and recursion. Indeed, the powers of the lab reside "in the special construction of laboratories in a manner which reverses the scale of phenomena so as to make things readable, and then accelerates the frequency of trials, allowing many mistakes to be made and registered." 15

It is clear that Latour's discussion is specific to the particular situations of that scientific practice and its relevance for issues of health, farms, animals, and more: a whole bundle of material and narrative factors emerge. But some of his perceptions facilitate thinking through a wide range of other lab practices as well, from the early technology and innovation laboratories to more recent versions of media and design labs. Indeed, as Latour elaborates, that laboratory's seeming containment is only relative, and "another reason why the inside/outside notion is irrelevant, is that in this example the laboratory positions itself precisely so as to reproduce inside its walls an event that seems to be happening only outside," emphasizing the lab as a scalar displacement of a lot of issues I debated on other levels.16

The particular narrative tropes and material experiments in the nineteenth and early twentieth-century already involved massive back-and-forth scalar operations. Not only facts were discovered or produced, but also other sorts of side products, including, for example, visions of the future that permeated the nineteenth century, as well as parapsychological realities measured in a lab, coated with the authority of the white garment worn by the specialist. A bundle of things emerged and spread, and became the add-on to the experimental product itself.

It is safe to say that the institutionalization of labs (from Bell Labs to Silicon Valley design labs, from Palo Alto PARC to various forms of MIT institutions, to the hack lab and creative lab scenes in Europe of the 1980s and 1990s) became crucial for the understanding of what we refer to as "media innovation." The massive financial investment in many forms of labs, especially in the US, was paralleled by the massive hyperbolic rhetoric that some of the places gained with their products. 
But they also produced practices and phrases with material impact across a cultural field. As John Beck and Ryan Bishop argue, the 1960s wave of Art and Tech labs was characterized by a future-oriented optimism: "the New Frontier, a world of the future that left behind the traumas of the recent past (the Depression, World War II) and cast an unblinking eye on the horizon ahead." 17 At the MIT Media Lab this was still later present in the central mantra "Inventing the Future," which, as Lori Emerson reminds, was a continuation of a particular sort of a humanism-future of an elite institution:

This particular brand of humanism is always tied to an imaginary future, it's a particular kind of inhuman humanism that began in the Arch Mach group and went on to flourish in the Media lab - it's one that constantly invokes an imagined future human that doesn't really exist partly because it's part of an ever-receding future but also because this imagined future human is only ever a privileged, highly individualized, boundary-policing, disembodied, white, western male human.18

Imaginaries are always caught in a web of political and economic conditions. Discourses of invention of the future as lab activity and the actual (admittedly often influential) work are expressions of normalized corporate interest in the untimely, the impossible, and fabulated dream worlds.19 Hence, as an I alternative I want to turn to some other situated practices of the imaginary as well as other sorts of media archaeology as ways to not only offer critical design and reverse-engineering, but as ways to pitch the lab's scalar effect as an invention of a different sort of a temporal horizon that orients toward the past. An invention of a technology (new or existing) is always an invention of a particular temporality.20

III

"How do you prototype the past?" is a question that has emerged as a guiding thread at the Maker Lab in the Humanities (MLab) at the University of Victoria. Led by Jentery Sayers, 
the lab is happily involved in the sort of a media archaeological stylistics that have become prevalent in many media theoretical writings and alternative histories. Sayers and Tiffany Chan talk about their lab as a site of media theory and design methodologies:

Technologies that no longer exist or function like they once did. The technologies we prototype are dated anywhere between the 1850s and 1950s, which give us a sense of media history prior to personal computing but after early feedback control and related mechanics. These prototypes usually inform present-day technologies - wearables, cloud computing, and optical character recognition, for example - by giving them a sense of texture and change. 21

As a sort of an inverted speculative design that focuses on the past, this approach resonates with Garnet Hertz's idea I of the past as a storehouse for invention.22 Yet it is clear that this is not imaginary media in the completely fabulated sense, even if it is explicitly interested in "absences in the historical record." 23 The institutionalized lab practice continues the maker-discourse by way of a practice-based history that picks up on established design technologies and techniques while also developing new ones like "the kit." A key part of the lab's design methodology (both conceptual and related to techniques of digital fabrication) are the "Kits for Cultural History," explained as a specific design/humanities approach to research:

Rather than communicating humanities research solely in a written format, these open-source kits encourage hands-on, exploratory engagements that playfully resist instrumentalism as well as determinism. In so doing, they prompt audiences to consider how the material particulars of historical mechanisms are embedded in culture, without assuming that, in the present, we can ever experience the world like "they did back then." 24

The kit becomes both a prop and a conceptual device more than an artifact. Its container is a sort of academic version of 
a Fluxkit, referring back to the projects of Fluxus. One kit, the "Early Wearable Technologies Kit," is a wooden jewellery box containing prototypes of Victorian electro-mobile

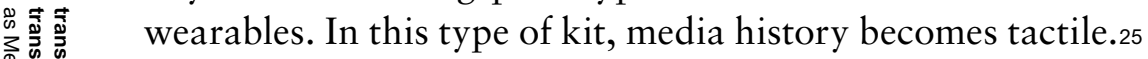
Another way to put this would be to say that the artifact or the product is itself a sort of a device for problematizing what is taken as "actual" past and the possible imaginaries around a particular technology or historical situation. It becomes a sort of a disjuncture on a time-axis and works to enrich the sense of the contemporary as an overlapping set of temporal layers. It is embedded in a rich world of considerations about the social relations and imaginaries that are stretched between actual pasts and potential presents, offering a disjuncture of temporal relations that should not be thought of only in the past-present-future directional sense. It is the playful resistance of the kit - a theme that resonates with what Geert Lovink called "against the grain" that produces an interesting rupture in too-easily taken-for-granted epistemologies of media time.26 The spatial affordance of the lab becomes such a rupture, and the institutional form of the lab becomes an affordance for a different sort of a temporality than "inventing the future."

An interesting version of a laboratory has been developed at the Berlin Humboldt University's Media Archaeological Fundus and the Signal Laboratory. Berlin is rich in other media historical sites, such as the project Atlas of MediaThinking and MediaActing, a cartography of media theory and practice. Site-specificity is similarly part of the appeal of the Fundus and the Signal Lab, but with a time-machine sort of approach. The Fundus is tightly premised around the theoretical work of Wolfgang Ernst, and itself a sort of a mix of collection, depo, and lab with a strong hands-on imperative. The sister space, the Signal Lab, is a related project that pushes teaching of media further from the texts of media theory to "teaching electronics, programming, and topics of the informatics/computer sciences from the viewpoint of media theory," as Stefan Höltgen puts it.27 This relates to the primacy of signal - the signal as the "object" of such analysis, or what Ernst emphasizes as the operational aspect of media: media are primarily 
media only when in operation, and when in operation, technical media function as time-critical devices.

The various object collections are not meant as collections in the archival sense. They are meant to be touched, investigated, they are not organized in an archival order but as laboratory experiments with a historical quality to them. The list of objectoddities would be long - from the familiar (Commodore 64s being the main feature of a recent intensive workshop/course at the Signal Laboratory) to the less obviously media-related, like the technical instruments in the Fundus including oscilloscopes and many other measurement devices. The spaces invert our usual sense of "Digital Humanities" focused on emerging techniques and data, reverse-engineering the functions of hardware. The objects are then lab apparatuses that fabricate ways to think of time: not so much the imaginary histories, but the ways in which specific techniques sustain our notions of time.

So these sorts of labs become stages for experiments and observation of time and the time-critical signal. As abstract as it sounds, this works in rather concrete terms of analysis. Ernst explains that "the essence of technical media is only evident in their operation implementation," which is to be understood through notions of time that should be further complicated in situations of analysis: "It is thus appropriate to employ concepts that do not always already bind technically signifying time figures to a transcendental signified and burden them with an imaginary called history." 28

In a curious twist as to the presence of lab cultures, what were new media labs some 100 years ago (including Menlo Park and others) would now be called media archaeology and other alternative media labs that engage with zombie media or speculative design of past media cultures. The novel technological objects of the late-nineteenth and early-twentieth centuries now become entry points to alternative sorts of approaches that partly feed into the charm and exoticism of old media. This also applies to film. Current film labs and other artist-run collectives are places of sharing both specific technical expertise and a sense of community around a "what's-not-yet-dead" sort of a spirit.29 This even applies to seemingly very techni- 
cal labs reminiscent of the (photo)chemical roots of modern technical media in their alternative lab practice. The Process Reversal Lab in the US is dedicated to being such an artistic "photochemical initiative" that, by way of a focused look at color film stock from earlier film cultures, also opens up a wider conceptual agenda as to what a technical-chemistry lab can be in the context of the imaginary:

In a time of discontinued film stocks, disenfranchised cinemas and abandoned film laboratories, the prospect of filmmaking can appear intimidating [...] as well as exciting - for while the film industry collapses all around us, we are being left with a unique opportunity; a chance to reinvent the medium in an image that was neither intended nor desired by its capitalist exploiters; one that explores new ways of seeing, new ways of hearing, and new ways of speaking about film.30

It would be tempting to look at such examples as proof of laboratory fever as a nostalgic drive toward resuscitating what has been lost and made irrelevant given the massive datadriven planetary-scale computational culture: an attachment to knowledge and retro sort of DIY culture surrounding rather obsolete things. But I would claim that it is also a much more interesting sort of practice as it deals with speculative pasts by way of technical knowledge, making interventions into technical practice in ways that are not reducible only to the digital. This becomes part of the temporal agenda of the lab, a theme that will be addressed in the next, final section.

Any discourse interested in speculative futures, alternative pasts, past futures, future pasts, and other sorts of contributions to the imaginary can also be confronted with questions about the spaces and situations in which imaginaries can happen.31 Developing such theoretical and methodological positions, we might even speak of location-specific theory that could be seen as a version of Peter Galison's call for specific 
theory that moves away from universalistic assumptions and also from narrow empiricism. As Rosi Braidotti suggests, this sort of specificity can frame a mixture of grounded, account-

I able, shareable, and open scholarly work.32

The lab, then, is one way to consider the situated nature of an institutional set-up. One particularly interesting aspect is how in some of the examples discussed, the site becomes both a hands-on design space and reverse-engineering space, which extends the idea of the imaginary from fabulation to other sorts of critical methodologies close to media archaeology too. And this sort of an extension is a way to intervene and invent new ways to deal with time that contributes to media theory and also to the debates about the post-digital as a particular way to approach media cultural time. It is important to ask about "the political anthropology of new institutional forms" while also acknowledging that an analysis of institutional situations can move beyond the merely human experi-

I enced.з3 Such a speculative design brief is also something that in these cases can be expanded to consider the other-times that are born in situations of critical labs in design and media archaeology: the time-critical technical media analyzed in the Signal Laboratory and the Media Archaeological Fundus that look at micro-temporalities that form a different level of manipulation of the time-axis than something that is returnable

I to the level of human perception.34 And this also involves the development of such technological critical practices that enable consideration of the linear time models of past-now-future as insufficient to understand the work of labs.

Geoff Cox has pointed to the politics of temporality in discussions about the post-digital, something that becomes relevant in the context of this text too. The notion of the post-digital is acknowledged as one way to discuss the asynchronous nature of contemporary media culture, which forces one to consider such temporal markers as "new" or "old" as

I inadequate.35 However, Cox flags that notions such as the post-digital also work as "periodizing concepts" which can

I actually hinder some of their critical potential.36 He continues by way of a discussion of the contemporary as a complementary concept that facilitates the development of sufficiently 
complex temporal forms that speak to practices and theory in contemporary art to media culture.

Besides the development of discursive insights to the axis of contemporary art and media, we should also consider in which spaces such a development happens. In this text, the lab is suggested as one such a situation, although we have to recognize that the variety of "labs" makes it impossible to make any generalizations: the "inventing the future" sort of corporate brand of MIT Media Lab differs rather radically from these small-scale examples that could be even called the "locavore" 37 humanities labs of our era, and they differ from the emergence of labs in rather different geopolitical locations such as the maker-lab ecosystems emerging in West Africa, for example in Agbogbloshie, Ghana, one of the hubs of e-waste dumping. The Agbogbloshie Makerspace Platform sounds at first like any maker lab/space, with its aims of collective work, community, and prototyping: "to join hands to prototype tools and co-create a hybrid digital-physical platform for recycling, making, sharing and trading." ${ }_{38}$ However, the material reality and infrastructure presents a different angle. The lab is placed in a second-order material reality of used things, which emerges out of necessity more than out of mere theoretical interest. But it is also a different geopolitical context in terms of electronic culture - another aspect that underlines the necessity to think of a politics of time in the post-digital culture as crucial entry point. We can consider this a geographical shift away from the usual narratives of US and European locations of invention to an alternative geopolitical angle. From the shift of the timeaxis of R\&D labs as inventions of the future to current labs aiming to invent pasts and alternative ways to engage with the now, the issue of labs becomes one way to frame imaginaries of media and design as situated practices.

1 This chapter emerges from the collective research project What Is a Media Lab that I am engaged in together with Lori Emerson and Darren Wershler. Please see www.whatisamedialab.com for more information.

2 Michel Foucault, "Afterword to the Temptation of St. Anthony," in Aesthetics, Method and Epistemology, ed. James. D Faubion (New York: New Press, 1998), 106.

3 To quote Gilles Deleuze, "the institution is always given as an organized system of means [...] law is a limitation of actions, institution a positive model for action." Gilles Deleuze, "Instincts and Institutions," Desert Islands and Other Texts 1953-1974 (Los Angeles: Semiotext(e), 2004), 19. 


\section{A. Imaginaries}

090

4 Friedrich Kittler, Gramophone, Film, Typewriter, trans. Geoffrey Winthrop-Young and Michael Wutz (Stanford: Stanford University Press, 1999), 10.

5 Ryan Bishop, "The Global University," Theory, Culture \& Society 23, nos. 2-3 (2006): 563-66.

6 Bureau D'Etudes speaks of the planetary lab: "Since World War, the planet is gradually transformed into a scale 1 laboratory. The old model of "world factory" has given way to the model of the "world laboratory." Objects of this laboratory, can we also be the subjects? Can we reclaim this huge machine that became autonomous and is now developing according to its own dynamic? Can we redirect the fate and direction of this laboratory?" Quoted on the Laboratory Planet website: http://laboratory planet.org/en/.

7 There are plenty of relevant examples, but in terms of recent activism where the rhetoric of the lab is mobilized as a feminist network, Deep Lab is a project that maps issues across activism, art, design, and internet culture: http://topicalcream.info/editorial/deep-lab-2/ (accessed September 20, 2016). It is also a good example of the ways in which the notion of the lab is not necessarily contained by normal architectural arrangements, but becomes a network of participants working on a wider geographical scale and with wider set of global social issues.

8 Geoff Cox, "The Post-digital and the Problem of Temporality," in Postdigital Aesthetics: Art, Computation and Design, eds. David M. Berry and Michael Dieter (Basingstoke: Palgrave, 2015), 151-62.

$9 \quad$ Alfred North Whitehead, Science and the Modern World (New York: New American Library 1925), 91.

10 Ibid., 92

11 See William Clark, Academic Charisma and the Origins of the Research University (Chicago and London: University of Chicago Press, 2006); Catherine M. Jackson, "Chemistry as the defining science: discipline and training in nineteenth-century chemical laboratories," Endeavour 35, nos. 2-3 (2011): 55-62.

12 Peter Galison and Caroline A. Jones, "Factory, Laboratory, Studio: Dispersing Sites of Production," in The Architecture of Science, eds. Peter Galison and Emily Thompson (Cambridge, MA: MIT Press, 1999), 497-540.

13 Edison's letter to Charles E. Buell, December 1, 1873, quoted in Paul Israel, "Telegraphy and Edison's Invention Factory," in Working at Inventing: Thomas A. Edison and the Menlo Park Experience, ed. William S. Pretzer (Baltimore: Johns Hopkins University Press, 2002), 69.

"Undergirding this new context was an emerging corporate culture that relied less on the invisible hand of the market and more on what historian Alfred Chandler has called the 'visible hand' of modern management." Paul Israel, "Telegraphy and Edison's Invention Factory," 66.

15 Bruno Latour, "Give Me a Laboratory and I Will Raise the World," Science Observed: Perspectives on the Social Study of Science, eds. Karin Knorr-Cetina and Michael Mulkay (London: Sage, 1983), 165 .

Ibid., 154.

John Beck and Ryan Bishop, "The Return of the Art and Tech Lab," article manuscript, April 2016.

Lori Emerson, "Selling the Future at the MIT Media Lab," lecture, transmediale, February 2016, Berlin, http://whatisamedialab.com/2016/02/17/selling-the-future-at-the-mit-media-lab/.

19 See Siegfried Zielinski, "Modelling Media for Ignatius Loyola: A Case Study on Athanius Kircher's World of Apparatus between the Imaginary and the Real," The Book of Imaginary Media: Excavating the Dream of the Ultimate Communication Medium, ed. Eric Kluitenberg (Amsterdam: debalie \& NAi Publishers, 2006), 28-55; Eric Kluitenberg, "On the Archaeology of Imaginary Media," Media Archaeology: Approaches, Applications and Implications, eds. Erkki Huhtamo and Jussi Parikka (Berkeley, CA: University of California Press, 2011), 48-69.

20 Wolfgang Ernst (2013) speaks of the Eigenzeit of media technology.

21 Darren Wershler, interview with Jentery Sayers and Tiffany Chan, "Prototyping the Past: The Make Lab in the Humanities at the University of Victoria," What Is a Media Lab project website, May 10, 2016, http://whatisamedialab.com/2016/05/10/prototyping-the-past-the-maker-lab-in-the-humanities-atthe-university-of-victoria/.

See Garnet Hertz, "Dead Media Research Lab," website, 2009, http://www.conceptlab.com/deadmedia/. http://visiblelanguagejournal.com/issue/172/article/1232.

24 Nina Belojevic, "Kits for Cultural History," Maker Lab in the Humanities, September 20, 2014, http:// maker.uvic.ca/kch/\#sthash.zd1Z4n21.dpuf. The "kit" also resonates strongly with some methods in critical design, like cultural probes, props, and scenarios. See Anthony Dunne, Hertzian Tales:

Electronic Products, Aesthetic Experience, and Critical Design (Cambridge, MA: MIT Press, 2005). 
The Lab Imaginary: Speculative Practices In Situ

091

25 Jentery Sayers, "Kits for Cultural History: A Critical Essay," Hyperhizz 13 (Fall 2015), http://hyperrhiz.io /hyperrhiz13/workshops-kits/early-wearables-essay.html.

26 Geert Lovink, My First Recession: Critical Internet Cultures in Transition (Rotterdam: NAi Publishers, 2004), 11

27 Interview with Stefan Höltgen, May 4, 2015.

28 Wolfgang Ernst, Chronopoetics: The Temporal Being and Operativity of Technological Media, trans. Anthony Enns (London: Rowman \& Littlefield, 2016), 205. See also Wolfgang Ernst, Sonic Time Machines (Amsterdam: Amsterdam University Press, 2016).

29 Good examples include the LaborBerlin film lab with its motto "film ain't dead" as well as a range of other European and other examples, such as Filmwerkplaats (Rotterdam, the Netherlands), Átomo 47 (Portugal), and the Filmkoop Wien (Austria). See Elena Duque, "Celluloid and Self-Sufficiency: ArtistRun Labs," CCCB Lab, Research and Innovation in the Cultural Sphere, February 23, 2016, http:// blogs.cccb.org/lab/en/article_cel\%C2\%B7luloide-i-autosuficiencia-laboratoris-autogestionats-per -artistes/.

30 "Process Reversal," Process Reversal Lab website, http://processreversal.org/. See also Duque, "Celluloid and Self-Sufficiency: Artist-Run Labs."

31 See Benjamin H. Bratton, "On Speculative Design," DIS Magazine, May 2016, http://dismagazine.com /discussion/81971/on-speculative-design-benjamin-h-bratton/; Media Archaeology: Approaches, Applications and Implications, eds. Erkki Huhtamo and Jussi Parikka (Berkeley: University of California Press, 2011); Richard Barbrook, Imaginary Futures: From Thinking Machines to the Global Village (London: Pluto, 2007); Reinhart Koselleck, Futures Past: On the Semantics of Historical Time, trans. Keith Tribe (New York: Columbia University Press, 2004).

32 Rosi Braidotti, The Posthuman (Cambridge: Polity, 2012), 157.

33 Brett Neilson and Ned Rossiter, "Towards a Political Anthropology of New Institutional Forms," Ephemera 6, no. 4 (2006): 393-410.

34 See also Bratton, "On Speculative Design."

35 Cox, "The Post-digital and the Problem of Temporality," 151; see also Florian Cramer, "What Is 'Postdigital,'" in Postdigital Aesthetics: Art Computation, and Design, eds. David M. Berry and Michael Dieter (Basingstoke: Palgrave, 2015), 12-26.

36 Ibid., 154

37 Lori Emerson, "The Archaeological Media Lab as a Locavore Thinking Device," May 12, 2011, https:// loriemerson.net/2011/05/12/archeological-media-lab-as-locavore-thinking-device/ (accessed May 27 , 2016).

38 The Agbogbloshie Makerspace Platform (AMP) website, https://qamp.net/project/ (accessed May 27 2016). 